\title{
Fiesta y ciudad en Talavera de la Reina en el Antiguo Régimen. Aspectos de la instrumentalización del espacio urbano en las fiestas
}

\author{
CésAR PACHeco JiMÉnez*
}

\begin{abstract}
RESUMEN
ABSTRACT

La fiesta, como fenómeno colectivo en

The fiesta, as a collective

el que influyen diversos factores, se articula en el espacio urbano y 10 instrumentaliza para adecuarlo a las necesidades del protocolo y del desarrollo propiamente festivo. En este articulo tratamos de plantear una aproximación a este asunto analizando el caso concreto de Talavera de la

Reina, donde los eventos celebrativos fueron frecuentes durante el Antiguo Régimen, entrando en juego diferentes recursos. Centramos el estudio en sus festividades más emblemáticas que servirán de apoyo para la interpretación de la hipótesis de la apropiación, transformación y disfrute de la calle y su entorno, en los días de regocijo. phenomenon on which several factors have influence, is articulated throughout the urban space, which orchestrate it to make it adecuate to the needs of the formalities and the fiesta itself. In this article we try to get closer to this matter analysing it in the town of Talavera de la Reina where the celebration of events were very frequent during the Ancient Regime. We will concentrate here on the most important fiestas and Holy days which will support the hypothesis of appropiation, transformation and enjoyment of the streets and its surroundings during the days of joy.
\end{abstract}

La fiesta, o el hecho festivo, es una faceta inherente a las sociedades desde la antigüedad; prácticamente surgen con la organización de las mismas y a través de las distintas formas y modos de planificarlas se irá de-

* Centro Asociado de la UNED. Talavera de la Reina. 
sarrollando la estructura de la festividad. Junto al sentido cíclico y crónico que tienen las fiestas, que vienen a marcar los tiempos sociales y ordenan las secuencias temporales de cada sociedad ', hay que añadir la necesaria participación e integración del colectivo humano para darle forma y argumentar su esencia. Como dice Schultz ${ }^{2}$, el individuo pierde una porción de su autonomía que sólo podrá encontrar en la comunidad y en esta comunidad cede su posición social en favor de la igualdad del festejo común.

Esta implicación del grupo, a veces con un claro matiz sociocéntrico, no conlleva, sin embargo, una absoluta liberación o eliminación de status social, ni siquiera en los días de "regocijo» y celebración. Ello en gran parte debido al fuerte encasillamiento que experimentan los grupos sociales en el Antiguo Régimen, época a la que nos vamos a referir preferentemente. Esta reglamentación rigurosa del orden interno de la misma sociedad se traduce en determinados rituales que la comunidad local organiza año tras año. En éstos, las vinculaciones a cada grupo social o profesional vienen a regir gran parte del aparato lúdico y celebrativo.

$Y$ en la medida en que la colectividad celebrante asume y reconoce la reglamentación del ritual festivo, fortaleciendo los estereotipos de la propia comunidad para marcar diferencias con los de comunidades vecinas, se fomentan las señas de identidad y se intensifican las relaciones locales. En palabras de Vovelle, "una fiesta cortejo o representación organizada, una manifestación y ostentación refleja la imagen que una sociedad más compleja desea darse a sí misma" ${ }^{3}$.

Concebir la fiesta como válvula de escape de la rutina diaria, en la que las clases inferiores se veían libres de las cargas del sistema, sirve para ilustrar una de las razones de la festividad. A propósito de la fiesta moderna, fundamentalmente la barroca, apunta Bonet Correa que la fiesta "con su mágico poder, con su hacer visible lo real maravilloso (deja) en suspenso la monotonía grisácea de la vida cotidiana, creando un espacio y tiempo utópicos» ${ }^{4}$. Hasta tal punto podía la fiesta convertirse en

\footnotetext{
VELASCO, Honorio M., "Las fiestas como procesos de identidad. Un estudio sobre algunos rituales en comunidades rurales madrileñas", Universidad y Sociedad, $n^{0}$ 8-9. Madrid, 1984, pág. 333. E. LEACH, Replanteamiento de la Antropología. Barcelona, 1961.

Schul.tz, Uwe, La fiesta, una historia cultural desde la antigüedad hasta nuestros dias. Madrid, 1993, pág. 13.

VOVELLE, Michel, "La fiesta en el campo de la historia de las mentalidades", Antropologia, $\mathrm{n}^{\circ}$ 11 (marzo 1996), pág. 26.

4 Bonet CORREA, Antonio, Fiesta, poder y arquitectura. Aproximaciones al barroco español. Madrid, 1990, pag. 5.
} 
Fiesta y ciudad en Talavera de la Reina en el Antiguo Régimen. Aspectos...

esta época en una especie de oasis para el pueblo, que acude a los recursos más ancestrales de ascendencia pagana cubriéndolos y maquillándolos de ortodoxia y devoción religiosas que las autoridades eclesiales están dispuestas a estructurar. En cuanto al orden del ritual, todo deberá ir según un protocolo organizado donde se resumen los diferentes grados de participación de acuerdo con un código establecido, que se expresa en ocasiones en las conocidas ordenanzas, y que serán garantes de la transmisión de esta memoria colectiva para evitar desviaciones circunstanciales.

Fiesta y ciudad van unidas estrechamente en la etapa moderna. Como bien dice Javier Portús "La fiesta urbana ha sido la manifestación colectiva por excelencia del Antiguo Régimen. A través de la ceremonia, el rito y la jerarquización de las grandes celebraciones, las sociedades han sabido identificarse como colectividad en la que cada uno de sus componentes tiene una función definida que cumplir» 5 .

La implicación religiosa de la fiesta moderna es indudable hasta el punto de que la mayoría de las celebraciones, aun de carácter profano, tienen una fundamentación devocional o al menos ligada a algunos de los aspectos de la estructura espiritual de los colectivos. A nivel institucional eclesiástico el fenómeno es patente. En el complejo período de los siglos $X V \mid$ al XVIII se dieron en Castilla numerosas formas de religiosidad que apuntaban a una diversidad de concepciones del culto, de representaciones de imágenes de su expresión en romerias, procesiones u otro tipo de festejos religioso-populares, además de la institucionalización de la devoción a través de cofradias o hermandades.

Pero existia al mismo tiempo un deseo por parte de la Iglesia Católica de que los valores intrinsecamente unidos al dogma se celebraran, vivieran y respetaran debidamente, tendiendo hacia la uniformidad y consiguiente homogeneización. Después del Concilio de Trento se observa en la jerarquía un empeño por regular y acabar con muchos excesos de la religiosidad popular, que socavaban las bases de un buen entendimiento de la religión; con ello querían reparar su tejado antes que los reformistas y

\footnotetext{
"Portus, Javier, "Algunas expresiones del orgullo local en la Sevilla del Siglo de Oro", Espacio. Tiempo y Forma, serie VII, $\mathrm{n}^{\circ}$ 4. Madrid, 1991, pág. 151. Acerca de esta relación entre festejos y ciudad pueden verse los trabajos siguientes: Victoria So 0 CABA. “Fiesta y ciudad en las noticias sobre la proclamación de Carlos IV". Espacio, Tiempo y Forma, serie VII, $n^{\circ} 3$. Madrid, 1990, págs. 259-271. Javier PIZARRO, “La entrada triunfal y la ciudad en los siglos XV1 y XVI», E.T.F., serie VII, $n^{\circ}$ 4. Madrid, 1991, págs. 121-134. M Pilar MONt t:agudo Robledo, "La ciudad en su dimensión festiva: Espacio y sociedad en los festejos valencianos de la Edad Moderna". Historia Social, $n^{\circ} 26,1996$, págs. 47-62.
} 
luteranos echaran más piedras sobre él. Fruto de este proceso se ensalzaron ciertos cultos y advocaciones para reforzar las creencias católicas. Se fomentó la veneración por las vidas ejemplares de los santos, tanto de los antiguos como de los que se canonizaron durante la Contrarreforma. Especial lugar tuvo la devoción mariana, con sus múltiples advocaciones, e igualmente otros misterios como el Santo Rosario - cuyas cofradías estuvieron muy vinculadas a la Orden de Santo Domingo- la Sangre de Cristo, o la singular exaltación del Santísimo Sacramento. Con respecto a este último fue prolífica la multiplicación de manifestaciones artísticas, religiosas y festivas que desbordaban en ingenio e imaginación para proclamar la Eucaristía.

\section{FESTIVIDADES DE LA TALAVERA MODERNA}

Como otras villas y ciudades castellanas, Talavera - urbe estratégica ubicada en una encrucijada de caminos entre dos zonas tan relevantes como Madrid y su corte, y las tierras extremeñas por otra partedisponía de sus propios recursos para el ocio colectivo y junto a las especiales ocasiones en las que el vecindario hacía demostraciones y regoçijos por motivos circunstanciales de diversa indole, existian unos determinados eventos festivos que cada año se repetían con mayor o menor esplendor.

Una relación de fiestas religiosas que se celebraban en las postrimerías de la Edad Media en la villa nos orienta en la estructuración del año festivo. Destacan "los días primeros de Pascuas, todas las fiestas principales de Nuestra Señora la Virgen María, e el día de Ramos e jueves de la cena, e viernes e sabados sanctos e el día de los Toros ${ }^{6}$ e otras semejantes fiestas principales» asi como «recibimientos de los reyes e reynas e nuestros prelados..." ? Esta dispersión de fiestas se mantiene casi intacta en los siglos posteriores, si bien adaptada a las nuevas concepciones y mentalidades.

Pero en la Talavera moderna asistimos a una constante tendencia al acto lúdico y a festejar cualquier ocasión. Sería preciso un marco más amplio para podernos extender en detallar las numerosas ocasiones en

Se refiere a la fiesta de los Desposorios de la Virgen y San José, que en Talavera se conoce por "Fiesta de las Mondas o de los Toros" por ser los actos taurinos los más relevantes.

Recogido en una sentencia contra el deán de la Colegiata de Talavera de 1449. Archivo de la Colegiata de Talavera, Caja $100, n^{\circ} 9$. 
que la villa organiza eventos sociales tanto de carácter religioso como profano en estas tres centurias. Pero sí podemos esbozar una aproximación tipológica de las fiestas que localmente tuvieron lugar. A partir de la casuística observada y el repertorio festivo que se registra en relaciones, crónicas, documentación municipal, libros capitulares de cabildos, cofradías, etc., se puede articular una clasificación de carácter metodológico. Distiguimos, pues, los siguientes tipos de festividades atendiendo a su naturaleza ${ }^{8}$ :

a) Fiestas religiosas del calendario litúrgico, entre las que destacaremos la del Corpus Christi.

b) Fiestas patronales de Nuestra Señora del Prado: Las Mondas, rogativas por diferentes motivos, traslados desde la iglesia mayor o Colegial a su ermita y viceversa.

c) Fiestas devocionales auspiciadas por cofradías o hermandades a los santos patronos.

d) Fiestas o celebraciones por recomendación de instancias superiores (Arzobispado, la Corona, el gobierno, etc.). Aquí se encuentran las que organiza el ayuntamiento juntamente con el cabildo de la Colegiata y curas de la villa, para celebrar eventos como el nacimiento de un miembro de la familia real, la firma de un tratado de paz, etc.

e) Honras fúnebres por miembros de la realeza, prelados, etc.

f) Recibimientos de prelados, reyes, infantes, o personalidades distinguidas.

g) Celebraciones por beatificaciones o canonizaciones de santos, normalmente promovidas por las órdenes religiosas a las que pertenecian y que tenian convento o monasterio abierto en la villa.

h) Celebraciones y festejos por la consagración de una nueva iglesia o ermita.

i) Fiestas relacionadas con reliquias de santos locales. público.

j) Festejos por la inauguración o terminación de una obra de interés

Esta propuesta nos sirve de base para una investigación que estamos realizando desde hace tiempo acerca de las fiestas locales y su expresión artistica, trabajo titulado Fiestas y Arte Efimero en Talavera, siglos xw-xvm. 
Esta clasificación, obviamente, es susceptible de revisión y no puede aplicarse a toda la casuistica local de cualquier ciudad. En esta ocasión, sin embargo, nos fijaremos más detenidamente en dos de las grandes fiestas representativas de la Talavera de esta etapa, dejando para otro momento el estudio pormenorizado de la relación de festividades aludidas.

\section{EL CORPUS CHRISTI}

La fiesta del Corpus Christi tuvo siempre una doble vertiente: el pueblo celebraba una fiesta, en eclosión procesional y espectacular, que ya en el siglo xvi era costumbre celebrar con desfiles fastuosos, con exhibición de "carros de representación" con personajes reales y elementos complementarios de pintura, escultura y textos literarios, para hacer más comprensibles las alegorias. Y por otra se exaltaba uno de los misterios de la fe que promovía la Iglesia con especial impetu.

Tomaremos este ejemplo de evento festivo para aplicar nuestra propuesta de interpretación sobre el problema de la instrumentalización del espacio urbano en las fiestas.

No disponemos de muchos datos sobre las celebraciones del Corpus en la Talavera medieval. Será a partir de la segunda mitad del siglo XVI, a raiz de las disposiciones tridentinas, cuando se aprecia una estructuración y dirigismo del proceso festivo, fenómeno que se puede comparar y analizar en muchos eventos de este tipo en el Antiguo Régimen ${ }^{9}$. Si bien en el caso de la diócesis de Toledo ya existían algunos precedentes en este sentido en las disposiciones sinodales bajo la prelatura del cardenal Tavera. El discurso utilizado para fundamentar la fiesta por uno de los cronistas locales, perteneciente a la Orden de San Jerónimo, fray Andrés de Torrejón, es significativo: «la reverencia del cuerpo de Nuestro Redentor que está en él real y verdaderamente como para confundir a los herejes que son lengua maldita niegan esta verdad infalible y por esta causa se celebra la fiesta (del Corpus) con tanta solemnidad y regoçijo" ${ }^{10}$. Esta fundamentación doctrinal tiene su expresión en el aparato estético y conceptual que mueve los diferentes elementos festivos, especialmente la

PAChe CO Jimenez. César, "La fiesta dirigida en el Antiguo Régimen: El Corpus Christi en Talavera en los siglos Xvi-XVm:, La Voz de Tajo. Talavera, VIII-IX 1992.

: Tohiaj Jon, Fray Andrés de, Libro de las Antigüedades de Talavera, su iglesia Colegial, Monasterios, parroquias, genealogias y barones ilustres...Talavera, 1596. Manuscrito de la B.N. sig., 1.498. 
procesión, máximo exponente de la demostración artística y apropiación del espacio, en cuanto que ésta marca un determinado recorrido dentro de la ciudad convirtiéndolo en "via sacra».

El reconocimiento de las procesiones del Sacramento en la sesión XIII del Concilio de Trento, el 11 de octubre de 1551, se hace patente cuando se declara que la costumbre de celebrar con veneración y solemnidad singulares un día festivo, con procesiones por las calles y lugares públicos, era "muy pía y religiosa y que el regoçijo de los fieles debía servir para que los herejes se consumieran de envidia y vergüenza y volvieran a la fe:s ${ }^{11}$.

En el desarrollo de estos cortejos tienen un papel especial las cofradías. Las que aparecen bajo el amparo de la advocación del Santísimo Sacramento fueron sin duda promotoras del aparato religioso-festivo del Corpus Christi en su vertiente devocional. Estas cofradias siempre contaron con el beneplácito y los favores de los sumos pontífices que las colmaban con privilegios diversos. En Talavera, la primera cofradia de este tipo se instituyó en 1541 en la parroquia de San Pedro a imagen de la cofradía romana de Santa Maria de Minerva e, igualmente, el papa Paulo III le concedió a sus cofrades indulgencias similares a la de Roma. Por influencia e impulso del padre fransciscano fray Juan de Salmerón, del convento de San Francisco de Talavera, se extendió a todas las demás parroquias talaveranas; en 1568, según cuenta Francisco de Soto en una crónica de la ciudad, "en todas las iglesias se hiceron grandes fiestas del Sacramento..." ${ }^{12}$. Como ya dijimos el carácter dirigista en expresiones devocionales y sobre todo en la organización de las procesiones en la Contrarreforma hicieron posible la concentración en manos de estas cofradías del aparato gestor de la fiesta religiosa del Sacramento ${ }^{13}$.

La celebración de la festividad del Corpus pasó por épocas de gran esplendor, pero también tuvo sus recesos debido quizá a que la estructura organizativa no estuvo en situación óptima para llevar el festejo a buen término. El referido cronista Soto se lamentaba de que "a pocos años a esta parte se ha dejado de hacer la procesión, no se con qué motivo, ni que razones pueden tener los cofrades para dejar de cumplir con esta obligación.... Lógicamente, influía la desestabilización de la práctica reli-

Caro Baroja, Julio. El estio festivo. Fiestas populares del verano. Madrid. 1986. pág. 62.

Soro. Francisco de. Historia de la antiquisima ciudad y colonia romana Elbora de la Carpetania, hoy Talavera de la Reina. Talavera, 1722.

BuRkF. Peter, La cultura popular en la Europa moderna. Madrid, 1990, pág. 77 
giosa y la mengua del exponente cultural que normalmente se canalizaba a través de instituciones como las cofradías.

Por otra parte, hay que preguntarse cuál era el papel que jugaba el ayuntamiento en estas celebraciones en una época en la que las implicaciones religiosas tenían una fuerte ascendencia hasta en el estamento y autoridades civiles. De hecho en la Administración del Antiguo Régimen es frecuente el talante de vinculación con el sector eclesiástico que define a las justicias y regimientos de las poblaciones, máxime trantándose de festividades de indole religiosa.

El corregidor y el cuerpo de regidores y justicias de la villa solian considerar detenidamente la preparación de las fiestas del Corpus. A menudo, en las cuentas de la Junta de Propios y Arbitrios aparecen los gastos ocasionados por la cera o los tablados puestos en estas fiestas, el ajuste con una compañía de comedias, etc. Como muestra del grado de implicación del consistorio en la preparación del festejo, y sus competencias en el acondicionamiento del espacio urbano para su celebración, sírvanos lo que se recoge en un acta del ayuntamiento de $1595^{14}$. En una de las sesiones se hace saber la necesidad de que "se adornen las calles y hagan altares" según noticia de un regidor, informando también del "repartimiento que an hecho açerca dello los ofiçios", es decir, los distintos gremios o corporaciones profesionales de la villa. Se observa un importante nivel de participación popular, canalizado sobre todo a través de estas organizaciones. El ayuntamiento, una vez enterado mandaba que "se guarde e cumplan desde agora para siempre y los dichos ofiçios y cada uno dellos los agan (los altares) e cumplan las personas que les toca sopena de diez myll maravedís, cubriendo las calles por arriva de suerte que no ofenda el sol". La cubrición de calles con toldos es una de las constantes del Corpus toledano, y como vemos práctica común en esta época.

Para estimular la dedicación del pueblo y de los maestros y oficiales a la fiesta, las autoridades ofrecian unos premios a los mejores altares de calle: «que se den de premio al mejor altar...seys ducados y al segundo altar que fuere tras el mejor quatro ducados y al tercero que fuere mejor tras el segundo dos ducados". Este método refuerza aún más el carácer dirigista que tenía la fiesta.

La dispersión y ubicación de los diferentes altares programados y los grupos responsables de los mismos se refleja en el siguiente cuadro:

\footnotetext{
14 Archivo Municipal de Talavera, Libro de Acuerdos de 1595, sesión 28 de abril. El acuerdo sobre "adereçar las calles los ofiçios el dia del Santissimo Sacramento".
} 
Fiesta y ciudad en Talavera de la Reina en el Antiguo Régimen. Aspectos...

Cuadro 1: Relación de altares colocados en la "carrera" de la procesión del Corpus Christi de 1595

\begin{tabular}{|c|c|c|}
\hline NN de altares & Lugar de ubicación en el plano urbano & Responsables \\
\hline 1 & $\begin{array}{l}\text { Puerta de convento de } \\
\text { San Francisco }\end{array}$ & Alfareros y olleros \\
\hline 1 & Convento de teatinos & Laborantes y tejedores de paños. \\
\hline 1 & Puerta de convento de teatinos & \\
\hline 1 & $\begin{array}{l}\text { Esquina de convento de } \\
\text { San Ildefonso }\end{array}$ & Herreros, cerrajeros y caldereros \\
\hline 1 & $\begin{array}{l}\text { Puerta de doña Bárbara en la } \\
\text { Calle Corredera }\end{array}$ & Carpinteros y albañiles \\
\hline 1 & San Salvador & La parroquia \\
\hline 1 & $\begin{array}{l}\text { Plazuela de Álvaro Cervantes } \\
\text { (hoy Aravaca) }\end{array}$ & Mesoneros \\
\hline 1 & $\begin{array}{l}\text { Puerta de las Alcantarillas } \\
\text { (o de la Villa) }\end{array}$ & $\begin{array}{l}\text { Diego López y Francisco } \\
\text { Gutiérrez }\end{array}$ \\
\hline 1 & San Miguel & La parroquia \\
\hline 1 & Santiago el Nuevo & La parroquia \\
\hline 1 & Plazuela del Lomo (del Potro) & $\begin{array}{l}\text { Sastres, calceteros, retaleros y } \\
\text { sombrereros }\end{array}$ \\
\hline Aderezo & Plaza de la villa (hoy del Reloj) & $\begin{array}{l}\text { Mercaderes de paños, de hierros, } \\
\text { cereros, cabestreros y esparteros }\end{array}$ \\
\hline 1 & $\begin{array}{l}\text { Santa Leocadia en esquina calle } \\
\text { de San Pedro }\end{array}$ & La parroquia de Santa Leocadia \\
\hline 1 & $\begin{array}{l}\text { Junto a puerta de la iglesia } \\
\text { de San Pedro }\end{array}$ & La parroquia de San Pedro \\
\hline 1 & $\begin{array}{l}\text { En la calle Empedrada, hoy } \\
\text { G. Alonso de Herrera }\end{array}$ & Zapateros y alambreros \\
\hline
\end{tabular}

(Fuente: Archivo Municipal de Talavera, Libro de Acuerdos de 1595).

La vistosidad de la fiesta conllevaba un esfuerzo en la preparación de ornamentos; éstos, aparte de engalanar suntuosamente los altares callejeros, debían arropar los balcones y ventanas, convirtiendo las calles en paseos multicolores decorados de verdes y rojos, "las grandes riquezas que ubo en los altares y calles por donde anduvo la procesión", nos dice el cronista Torrejón. Esa exhuberancia es recogida a menudo por las relaciones festivas; a modo de ilustración sirvan aquellos versos de la obra de don Miguel Matías de la Llave describiendo la Corredera en las fiestas de rogativas de 1775 con la Virgen del Prado: 
"Vistosa se mostró la Corredera al paso de la Reina en este día... los dueños de sus casas placentera hicieron con brocados su alegría obstentando en ventanas y balcones sus gratos y devotos corazones" ${ }^{15}$.

La presencia del elemento vegetal es importante, y al ser tan considerable en estas festividades del comienzo del estío indica, como apunta Caro Baroja, su condición de festejo-homenaje a la fertilidad del componente vegetal. Pero no sólo como adorno de calles y casas, sino también en la representación de animales que la creatividad popular diseñaba ${ }^{16}$.

El otro de los elementos típicos de la fiesta era la luz; vencer las tinieblas durante la noche era el propósito del despliegue que se montaba de luminarias, fuegos y fogatas en plazas, calles y edificios principales. En las fiestas de 1682, por ejemplo, los mayordomos de la Cofradía del Corpus en vez de luminarias tuvieron encendidas 150 hachas de cera blanda, sistema éste que parecía enorgullecer más aún a los organizadores. Las «invenciones de pólvora" o fuegos de artificio, que tan relevante papel jugaron en la fiesta barroca, eran un recurso usado en numerosas ocasiones.

Junto a esto el resto de actividades lúdicas y de entretenimiento, como las comedias, los juegos, los certámenes poéticos de Minerva ${ }^{17}$, eran parte inherente del proceso celebrativo del Corpus.

\section{LA FIESTA DE LAS MONDAS O DE LOS TOROS}

La cuestión de la fiesta popular trae consigo muchos flecos de análisis y no pocas dificultades de interpretación. En el caso de las

15 Matias de La Li.ave, Miguel, Relación puntual de las plausibles fiestas, hechas en la mui noble, antigua y lea villa de Talavera, con motivo de llevar a su hermita a su benefica Patrona. Madre y singular Protectora, Maria Santisima del Prado...Talavera, 1775. Mss. del Archivo Municipal de Talavera. Fondo «Ermita del Prado».

16 Torrejón menciona unas «invenciones de animales hechos de yerbas» en las celebraciones del Corpus de 1568 , a los que hay que atribuir un alto significado simbólico

Disponemos de uno bien conocido en Talavera, que se celebró en la Parroquia de San Pedro en 1631, y del que afortunadamente nos ha llegado parte de su documentación, vid. MADROÑaL. Abraham y López GayARRE. Pedro, "Una justa poética desconocida celebrada en Talavera en 1631". Cuaderna: Revista de estudios humanisticos de Talavera y su antigua tierra, n 5 , Talavera, 1997, págs. 87-102. En el texto se hace relación asimismo a los testejos del Corpus de ese año con el título "Siguense las fiestas que la perrochial del Señor San Pedro celebró al SS. Sacramento por sus cotadres en su iglesia, este año de 1631 ". inserto en Protocolo notarial $n^{\circ}$ 15.900 del Archivo Histórico Provincial de Toledo. 
Fiesta y ciudad en Talavera de la Reina en el Antiguo Régimen. Aspectos...

Mondas ${ }^{18}$ puede rastrearse una fase antigua en la que el factor popular era de gran importancia en el desarrollo del ritual. Llega un momento, que fijamos en los albores de la época moderna -principios del siglo XVI- en el que la comunidad vecinal, compuesta de elementos privilegiados y populares, tiene necesidad de vertebrar la celebración en aras de un control por parte de las clases dominantes.

Este control representa la culminación de un proceso en que la tradición tiene un peso específico. La ordenación de cada paso del ritual festivo, el papel que juegan las clases privilegiadas en el disfrute de cada fase, así como el espacio residual que protagoniza el pueblo, sobre todo en el acto celebrativo de los juegos taurinos, viene a plasmar toda una larga y fecunda tradición religioso-festiva del rito de las Mondas. Durante la Edad Media debió de fraguarse un peculiar estilo de festejar la fiesta mariana, donde la vinculación al toro es innegable.

No en vano, en el documento de $1507^{19}$, se evoca una tradición asumida por la comunidad en todos sus elementos: «...por quanto la fiesta de los toros que en esta villa se a fecho de inmemorial tiempo a esta parte e cada un año se haze a onor e reverencia de Nuestra Señora...". En todo esto el factor «tiempo", como categoría influyente en la sucesión crónica de la festividad, es referente de la memoria colectiva. El eje vertebrador del exponente lúdico, por el cual se adapta la fiesta a una doble vertiente: lo pretérito y el tiempo venidero.

\footnotetext{
Acerca de las Mondas existía una escasez bibliográfica que ha ido subsanándose con la publicación de algunos documentos relacionados con la fiesta. Los estudios más acertados sobre el hecho y orígenes de la festividad son los siguientes: Julio CARO BAROJA, "Las Mondas de Talavera", Ritos y mitos equivocos. Madrid, 1974. Ma Pia TIMÓN TIEMBLO, "Fiestas de primavera: Las Mondas talabricenses", Narriá, n9, 1978, págs. 18-20. Ángel Ballestefios Gallahdo, Las Mondas de Talavera de la Reina: Historia de una tradición. Toledo, 1980. Sobre el aspecto taurino de las mismas vid. Guillaume-Alonso, Araceli, "De los ritos taurinos y su evolución en los siglos XVI y XVH: Las Mondas de Talavera o fiesta de los Toros", Cuaderna, n² 2. Talavera, 1995 págs. 118-128. Por lo que respecta a la edición de sus fuentes hay que destacar: Mariano Maroto GARRIDO, "La reorganización y ordenación de las Mondas en 1603", Cuaderna, n 2. Talavera, 1995, págs. 129-145. Mariano Garcia Ruipérez y Pedro Lopez Gayarre, Mondas, dos momentos dos documentos. Años 1507 y 1803. Talavera, 1992. De los mismo autores la transcripción y la edición de Las ordenanzas de las fiestas de las Mondas. Año 1515. Talavera, 1990 y PENA TERRONES, Juan de la, Relación de las fiestas de Talavera llamada "Mondas". Año 1668. Talavera, 1989. Fray Antonio de AyalA, Compendio y relación de la Muy Noble y Muy Leal Villa de Talavera de la Reina, descripcion de sus solemnes annuales fiestas, que llaman de las Mondas. Talavera, 1696. Edición facsímil. Talavera. Excmo. Ayuntamiento, 1993. PACHECo, César (edición), "De la fiesta y solemnidad que se hace a Nuestra Señora cada año después de la Resurreçión" (Libro de Antigüedades de Talavera de fray Andrés de Torrejón, 1596). Talavera, 1997
}

Garcia Ruiperez. Mariano y Pedro Lopez Gayarre, Mondas, dos momentos, dos docu mentos. Años 1507 y 1803. Talavera, 1992. 
Celebrar un evento religioso festivo, teniendo presente los antecedentes más lejanos del mismo, nos sitúa en una conexión entre el pasado y el futuro ${ }^{20}$. En las Mondas, el discurso tradicional se convierte en un deseo de perpetuidad en el que las autoridades fijan, ordenan, regulan y controlan el desarrollo del hecho celebrativo.

Dentro de este marco de fiesta, tradición y rito, es donde podíamos enclavar las coordenadas de las Mondas. Amén de su vertiente religiosa y devocional, sobre la que cabrian muchas especulaciones en la dicotomia: religiosidad popular-religiosidad oficial, la vinculación a la figura taurina es de enorme importancia.

La fiesta llamada de Las Mondas, y antiguamente "de los Toros", nos obliga a una puesta al día en una revisión de los materiales interpretativos y del sentido estructural de la fiesta. Por la importancia que tiene para historiadores, etnólogos o antropólogos, Las Mondas representan un campo de investigación que exige la afinación de las fuentes en las que se basa y que, en gran medida, han ido consolidando una determinada forma de concebir y organizar el hecho festivo.

En primer lugar, asistimos a una imponente valoración de lo taurino dentro de esta fiesta, donde la organización institucional del rito por las clases dirigentes y privilegiadas se va potenciando desde el siglo $x v{ }^{21}$. En realidad como sucede en otros pueblos con procesos históricos similares, asistimos a un control de la manifestación lúdico-religiosa frente a posibles desviaciones y excesiva versatilidad del elemento popular.

La "fiesta de los toros" es un ejemplo del papel relevante que juega en los ritos hispánicos el toro, lo táurico y lo festivo unidos en perfecta conjunción para reforzar la identidad de la comunidad vecinal y dejar bien clara su estructura social ${ }^{22}$.

Las ordenanzas de 1515, fijadas por el cabildo de la Colegiata, los curas beneficiados de las diferentes parroquias y el Ayuntamiento, fueron degradándose progresivamente durante el siglo xv।. Algunos puntos fueron

Cox, Harvey, Las fiestas de locos: Ensayo sobre el talante festivo y la fantasía. Madrid. 1983, pág. 40.

La expresión más clara de ese intento de control e institucionalización de la devoción a la Virgen del Prado y sus festejos es la creación en 1538 de la Hermandad de Nuestra Señora del Prado, donde el elemento caballeresco e hidalgo de la villa tiene el absoluto predominio. Las or denanzas de esta hermandad pueden consultarse en una moderna edición: Ordenanzas de la Hermandad de Nuestra Señora del Prado, años 1536, 1850, 1926 y 1973. Talavera, 1991.

Acerca de este aspecto en la fiesta de las Mondas ver Guillaume-Alonso, Araceli, op. cit. 
alterados y el rito fue perdiendo su carácter original. Esta mutación y desorden en el protocolo lleva a las autoridades firmantes a juntarse de nuevo en 1603 para remediarlo. Conscientes de los excesos que se cometían en torno a la compra de los toros para ser corridos en las distintas parroquias, era necesaria una revisión de las ordenanzas y poner al día aquellos artículos que podían haberse quedado obsoletos. Todo ello quedó reflejado en las nuevas ordenanzas de $1603^{23}$, que venían a reformar las de $1515^{24}$.

Son varias las fuentes cronísticas que nos relatan con más o menos detalle el desarrollo de las distintas partes del festejo y su expresión social ${ }^{25}$. En la estructura de la misma subyace un fuerte componente devocional que se conjuga con las elementales tendencias lúdicas de la comunidad. El recocido prestigio que alcanza el santuario de Nuestra Señora del Prado como centro de culto no sólo local sino comarcal ${ }^{26}$, influye en ese carácter de proyección más amplia que tiene las Mondas. No en vano este tipo de fiestas, basadas en las ofrendas de los productos de la tierra por parte de los comarcanos y vecinos de la villa incide en que el cortejo propiamente dicho adquiera un especial relieve. Una comitiva donde participan tanto el sector oligárquico y el popular, el eclesiástico y el civil, el local y el comarcal.

Teniendo en cuenta esa vertiente exclusivamente urbana del periplo procesional, las Mondas suponen una interesante muestra de cómo la ciudad es utilizada como recurso compositivo del discurso festivo, aspecto que trataremos a continuación.

\section{FIESTA Y ESPACIO URBANO}

Desde el punto de visto del análisis del binomio fiesta/ciudad, es el periplo del cortejo procesional lo que más interés despierta para comprender

\footnotetext{
Maroto, Mariano, op. cit.

Las ordenanzas de las fiestas de Mondas. Año 1515. Transcripción de M. García Ruipérez y P.A. López Gayarre. Talavera, Excmo. Ayuntamiento, 1990 (Facsimiles, $n^{0} 2$ ).

25 Debido al carácter de este trabajo no nos extenderemos en la exposición del proceso festivo de las Mondas, para lo cual remitimos al lector a la bibliografia apuntada en la nota 17.

?e En efecto, la ermita de Nuestra Señora del Prado, situada extramuros de la villa, en e sector este y próxima al Camino Real hacia Madrid, adquirió un reconocimiento en el siglo Xvi como uno de los muchos santuarios de interés comarcal que había en el reino. Vid. William A. Christian, "Panorama de las devociones a santuarios españoles desde el principio de la Edad Media hasta nuestros días". Temas de antropología española, LISON TOLOSANA, Carmelo de. Madrid, 1976.
} 
esa aludida instrumentalización del espacio urbano. Si observamos algunos de los planos en los que se marca la trayectoria seguida por las comitivas en distintos tipos de fiestas en Talavera, hallamos una constante utilización de espacios fijos, como la plaza del Pan o plaza pública o de la villa, y algunas calles de sus aledaños, incluyendo las que necesariamente forman parte del Camino Real, desde la Puerta de Cuartos hasta la Puerta de Toledo, extremos oeste y este respectivamente de la villa en esta época. Zonas marcadas por una constante exhibición a lo público, a lo colectivo. Frente a los rincones de la villa caracterizados por un eminente sentido residencial y en cierta medida con condicionantes de la posición socio-económica de sus moradores ${ }^{27}$, las calles y plazas del universo festivo representan ese espacio "neutro" que nos apunta Consuelo Gómez, que se les atribuye, sujetos a esa instrumentalización estética en manos de los diferentes poderes y de la manifestación de sus intereses e ideología ${ }^{28}$.

Como hemos visto en el caso del Corpus Christi, los gremios, como entes corporativos, articularon su participación mediante la atribución de ciertos espacios del recorrido procesional que si bien el regimiento distribuía de acuerdo a las normas ordenancistas, esta operación venía a responder a la realidad socioprofesional del tejido urbano. Cada calle o área solía especializarse en algunos oficios, de modo que el espacio público queda impregnado de unas actividades artesanales o mercantiles que toda la comunidad acepta y legitima. Esta interesante correspondencia entre gremialización y uso de espacios en el trayecto del cortejo festivo nos sitúa ante una constante de esa instrumentalización del espacio urbano que se produce en las fiestas. Es el recorrido marcado por las autoridades con una intencionalidad clara y específicamente diseñada a partir de los centros de interés. Lo que Victoria Soto denomina "eje del poder» ${ }^{29}$, es

\footnotetext{
Determinados barrios de la villa quedaron siempre fuera de los itinerarios de esas "via sacrae" de las festividades. Por el carácter marginal que tenia. por ejemplo, el barrio de la Puerta de Cuartos, área de los vecinos labradores y trabajadores en su inmensa mayoria, no fue considerado por los organizadores de estos cortejos sino en puntuales ocasiones, como el paso de algún personaje relevante a través de algunas de sus calles por formar parte de Camino Real intraurbano, o cuando la fiesta tenía por objeto algún edificio del barrio, como la consagración de la parroquia de San Andrés en 1560 o la del convento de padres carmelitas en 1711. PACHECO, César, El barrio de la Puerta de Cuartos: Historia social y cultural. Talavera, 1993.

Gómez LoPEz, Consuelo, "La instrumentalización de los espacios urbanos en los siglos XVI y xvIl: El ejemplo de la Plaza del Mercado de Alcalá de Henares". Espacio. Tiempo y Forma. serie VII, $n^{\circ}$ 5. Madrid, 1992, pág. 166.

SOTO CABA, Victoria, "Fiesta y ciudad en las noticias sobre la proclamación de Carlos IV", Espacio. Tiempo y Forma, serie VII, nํ⒊ Madrid, 1990, pág. 268
} 
decir una carrera o ruta intraurbana que va pasando por determinados lugares representativos del poder político, religioso o económico locales. Es lógico, por tanto, que en eventos tan importantes como éste, donde la representación y la apariencia suponian alardes de demostración exterior, el cortejo procesional pasara por las zonas neurálgicas de la villa. En este caso, por calles tan céntricas y concurridas de la actividad urbana como la Plaza del Pan o Santa María, de donde se parte y adonde finaliza el cortejo. La Corredera que junto con la de Zapaterías o Toledo -donde se ubicaba el convento de San Francisco- era el eje interior del Camino Real de Madrid a Extremadura ${ }^{30}$, en cuyo entorno se localizaban los conventos de los padres teatinos, hoy calle Palenque, y el de agustinas de San Ildefonso; la plaza de la villa o del Comercio, centro mercantil por excelencia de la urbe, así como zonas residenciales de hidalgos y caballeros como la plaza de Aravaca, la colación de San Miguel y Santiago, etc.

La procesión necesita unas especiales condiciones para su desarrollo, tanto en el plano espiritual y religioso de los participantes, como en la infraestructura urbana y expositiva que acompaña la "carrera». Estos elementos son de enorme interés para comprender la esencia de la fiesta moderna y su vinculación al planteamiento doctrinal y catequizador del Corpus Christi.

La vertiente estética era muy importante en las fiestas del barroco donde la teatralidad de las manifestaciones exteriores en el ámbito urbano producen un desarrollo del concepto escenográfico. Lo que de por si es feo o rompe la armonía se recubre, se maquilla o se repinta, dentro de una campaña por cambiar el aspecto cotidiano que tienen las calles, plazas o edificios representativos. Por ello el ornato y esfuerzo decorativista que las autoridades hacen siempre a la hora de organizar las fiestas, junto al tan manido concepto del "decoro» que está en boga en esta época, siempre es poco. Desde el ayutamiento se manda a los vecinos que cuelguen tapices, brocados, telas y sedas, que puedan cubrir ventanas, puertas y balcones; otras veces se montan estructuras de arquitecturas efimeras que ofrecen un maravilloso e irreal colorido a las pobres y sombrías fachadas de edificios. Los arcos triunfales decorados con pinturas, jeroglíficos, invenciones, animales, y un sin fin de creativos recursos y artificios

Sobre el callejero talaverano de esta época pueden consultarse nuestros trabajos: PACHECo, César, "La transformación del espacio urbano de Talavera de la Reina en el siglo XVI", Espacio, Tiempo y Forma, serie VII, $n^{\circ} 7,1994$, págs. 73 y ss. También PACHeCO, César y DiAL, Benito "Callejero histórico I: La Corredera del Cristo". Cuaderna: Revista de estudios humanisticos de Talavera y su antigua tierra, $n^{\circ}$ 4. Talavera, 1996, págs. 118-125. 
buscan, además de su valor simbólico en el discurso festivo, una constante admiración por parte de los participantes, el «regoçijo" que continuamente despierta este tipo de expresiones.

Las puertas de las murallas en Talavera, por ser elementos singulares del urbanismo de muchas villas y ciudades, sirvieron como puntos de referencia en el trazado de los cortejos; pero además, fueron utilizadas en muchas ocasiones para albergar en sus muros esos montajes fruto de la imaginación y del fructífero espíritu artístico empleado para la fiesta. En Talavera, contábamos con un ejemplo de funcionalidad de una puerta puesta al servicio del hecho festivo. El Arco de San Pedro, una de las puertas principales del primer recinto amurallado, cerca de la plaza pública del Comercio (hoy del Reloj), se ubicaba en un punto estratégico de todos los itinerarios festivos. Su especial situación era óptima para una proyección iconográfica que a la vez que servía de ornato de la muralla para esta calle era una referencia devocional, al modo de los altares o capillitas de calle que se pueden encontrar en muchas ciudades. Hacia 1660, según refiere el cronista local Ildefonso Fernández ${ }^{31}$, se pintaron en su cara norte, mirando hacia la referida plaza, un gran conjunto de pintura mural que representaba la exaltación del Santísimo Sacramento. Con un programa iconográfico que incluía figuras alegóricas de la $\mathrm{Fe}$, representaciones de Santo Tomás de Aquino, personajes bíblicos, y por supuesto una custodia sostenida por dos ángeles ${ }^{32}$. Es fácil comprender el valor simbólico-religioso que muchas manifestaciones artísticas tenían en el barroco. La configuración escenográfica en este mural tenía una función concreta vinculada a la fiesta del Corpus, que ya subrayó Fita: "la razón de haberse trazado... fácilmente se trasluce o se deja entender si observamos que las suntuosas celebridades del Corpus, que atraian a innumerable gentío, tuvieron su primer origen y centro principal en el templo de San Pedro...", iglesia que estaba situada a escasos metros de las pinturas.

Posiblemente no fue éste el único ejemplo estético de carácter permanente que hubo formando parte de la «via sacra». Pero su existencia nos sugiere un intento de fijación escenográfica supeditada a la celebración festiva.

Fernandez y Sanchez, Ildefonso, Historia de la Muy Noble y Muy Leal Ciudad de Talavera de la Reina. Talavera, Imprenta Rubalcaba,1896, pág. 172.

Acerca de este arco y sus pinturas el padre Fidel Fita realizó poco antes de su demolición, ocurrida en 1886, un estudio que publicó con el título "El Arco de San Pedro en Talavera de la Reina", Boletín de la Real Academia de la Historia, tomo IV. Madrid, 1885. En nuestro trabajo La pintura mural del siglo xvili en Talavera (en prensa), nos ocupamos de esta manifestación artística en el espacio público. 
Fiesta y ciudad en Talavera de la Reina en el Antiguo Régimen. Aspectos..

Por último, nos referiremos a una actividad inserta en el proceso celebrativo de las Mondas que aporta un componente novedoso al uso del espacio sociourbano. Juan de la Peña Terrones, en 1668, nos relata la siguiente costumbre que tenía lugar el viernes de la semana festiva: "se juntan los caballeron hermanos en la plaza del Comercio a caballo, con ricos aderezos los jinetes y vistosos arreos en los caballos; corren la calle de la Zapatería abajo... los caballeros todos con costosísimos vestidos de color, valonas de puntas, plumas en los sombreros, borceguíes y zapatos de baldés blancos, desde la torre del reloj hasta el pórtico del convento de San Francisco, al son de clarines, y habiendo corrido la primera carrera cada uno de por sí, corren la segunda, que es por parejas...luego después entran a correr vaqueros y otras personas que han harto regoçijo y que reir..." ${ }^{33}$. Esta apropiación de la calle mediante la carrera por parte de los elementos privilegiados de la comunidad es una manera de afirmar su supremacía y de la toma de posesión simbólica del espacio festivo. Ritual de alarde caballeresco delante del público que se hacía también en la plaza mayor (del Pan) donde tenían lugar las principales corridas y juegos taurinos.

En efecto, la plaza toma funciones de coso, y con ello se transforma su aspecto con el montaje de talanqueras, toriles, barreras, etc. Cada año el Ayuntamiento ajustaba con carpinteros el acondicionamiento de ésta y otras plazas de la villa en las que se corrían toros ${ }^{34}$. Se convertía la ciudad en un verdadero recinto taurino, donde las calles y las plazas son tomadas por los toros y las gentes, en ese juego ancestral entre el individuo y el animal. Cada parroquia tenía instrumentalizada la plaza, o espacio abierto próxima a ella -en ocasiones incluso los cementerios eran escenarios de este tipo de corridas - donde se celebraban los festejos taurinos; cada barrio o colación disponía así de su propio "microcosmos lúdico».

En una primera fase del festejo se procedía al divertimento del vecindario en múltiples espacios periféricos, equidistantes de ese núcleo central

De la Pena Terrones, Juan, op. cit.

34 En la escritura de remate de los tablados y plazas para la fiestas de 1754 se recogen las siguientes condiciones: "Francisco Díaz de Enzinas y Antonio Diez y Diego de Abila(maestros de albañileria y carpintería) vecinos desta villa, como mejor prozeda dezimos que hazemos postura en las plazas de esta villa y la de ermita de Nuestra Señora Santa María del Prado estramuros de ella para las fiestas prinzipales proximas de este presente año... en condizión que se nos ha de dar toda la madera y puertas de que se componen el toril de la plaza del Pan como también las puertas que zierran dicha plaza... yten que ha de ser de nuestro cargo serrar las dos plazas y calle para los enzierros y hazer el toril de la Puerta de Toledo y todo según costumbre..." Archivo Histórico Provincial de Toledo, Protocolo n 15.291, fol 49r. 
de la fiesta que era la plaza Mayor o del Pan ${ }^{35}$, para pasar posteriormente a la convención de los recursos en un mismo punto, en una sola fiesta, en una sola expresión del rito táurico, apoyada por la colectividad.

La esencia pues del uso del espacio urbano en el tiempo festivo nos sugiere una lectura directa de la mentalidad que en cada época atribuye a los espacios privilegiados y a los residuales del hábitat humano. Colmando a unos de significación simbólica, religiosa, sagrada, funcional, etc. y a otros relegándolos a una zona de transición entre el mundo real y el imaginario, cuando no en puro escenario del devenir cotidiano sin más implicaciones de tipo trascendental. A su vez, se ve sometido en las fiestas al manejo que el poder ejerce sobre el entramado urbano, condicionando su aspecto y su versatilidad.

\section{APÉNDICE: ITINERARIOS URBANOS DE ALGUNAS FIESTAS DE TALAVERA}

Corpus Christi de 1602

* Iglesia Colegial

* Plaza del Pan

* Calle de Puerta Nueva (Palenque)

* La Corredera

* Plaza del Salvador

* Plaza de Aravaca

* Plaza de San Miguel

* Calle de Marquesitas

* Calle Cerería

* Plaza pública (del Reloj)

* Arco de San Pedro

* Calle Empedrada (G. Alonso de Herrera)

* Plaza del Cardenal Tenorio

* Iglesia Colegial
Procesión de los gallegos en las

Mondas del siglo xvil

* Ermita de Santos Mártires en la Enramada

* Puerta de Zamora

* Santiago el Nuevo

* Calle Mesones

* Plaza pública (del Reloj)

* Calle San Francisco

* Puerta de Toledo

* Convento de la Trinidad

* Ermita de San Juan

* Humilladero del Prado

* Ermita de Nuestra Señora del Prado

Cortejo de Mondas. Siglo XvII

* Desde parroquia de Santiago el Nuevo

35 La plaza del Pan, centro neurálgico a nivel político, administrativo y festivo, asumia desde la Edad Media esa funcionalidad para el festejo y el evento público en general. Sobre su evolución y remodelación a finales del siglo XVi para convertirla en una gran plaza mayor vid. PACHECO, César, "La transformación del espacio urbano de Talavera de la Reina en el siglo Xvi". Espacio, Tiempo y Forma, serie VII, no 7. Madrid, 1994, pág. 80. 
Fiesta y ciudad en Talavera de la Reina en el Antiguo Régimen. Aspectos...

* Calle Mesones

* Plaza pública (del Reloj)

* La Corredera

* El Salvador

* Calle Charcón

* Puerta de la Miel

* Puerta de Mérida

* San Clemente

* Calle de los Grifos (Adalid Meneses)

* Plaza Mayor o del Pan

* Calle Empedrada

* Arco de San Pedro

* Calle San Francisco
* Puerta de Toledo

* Convento de la Trinidad

* Ermita de San Juan

* Humilladero del Prado

* Ermita de Nuestra Señora del Prado (A la vuelta)

* El Prado

* Calle Cristo de la Guía

* Puerta del Sol

* Calle del Sol

* Plaza pública (del Reloj)

* Calle Mesones

* Iglesia de Santiago el Nuevo

Paso de la reina de Portugal doña Mariana de Borbón en 1777

* Camino Real de Extremadura

* Puerta de Cuartos

* Calle Puerta de Cuartos (Juan de Mariana)

* San Andrés

* Calle del Carmen

* Puente y calle del Pópulo

* La Corredera

* Plaza pública (del Reloj)

* Calle San Francisco

* Puerta de Toledo

* Camino Real a Madrid

Consagración del Convento del Carmen

de Padres Carmelitas. Año 1711

* Iglesia Colegial

* Plaza del Cardenal Tenorio

* Calle Empedrada

* Arco de San Pedro

* Plaza pública (del Reloj)

* La Corredera

* El Salvador

* Arco y puente del Pópulo

* Calle del Carmen

* Plaza de San Andrés

* Convento de PP. Carmelitas. 


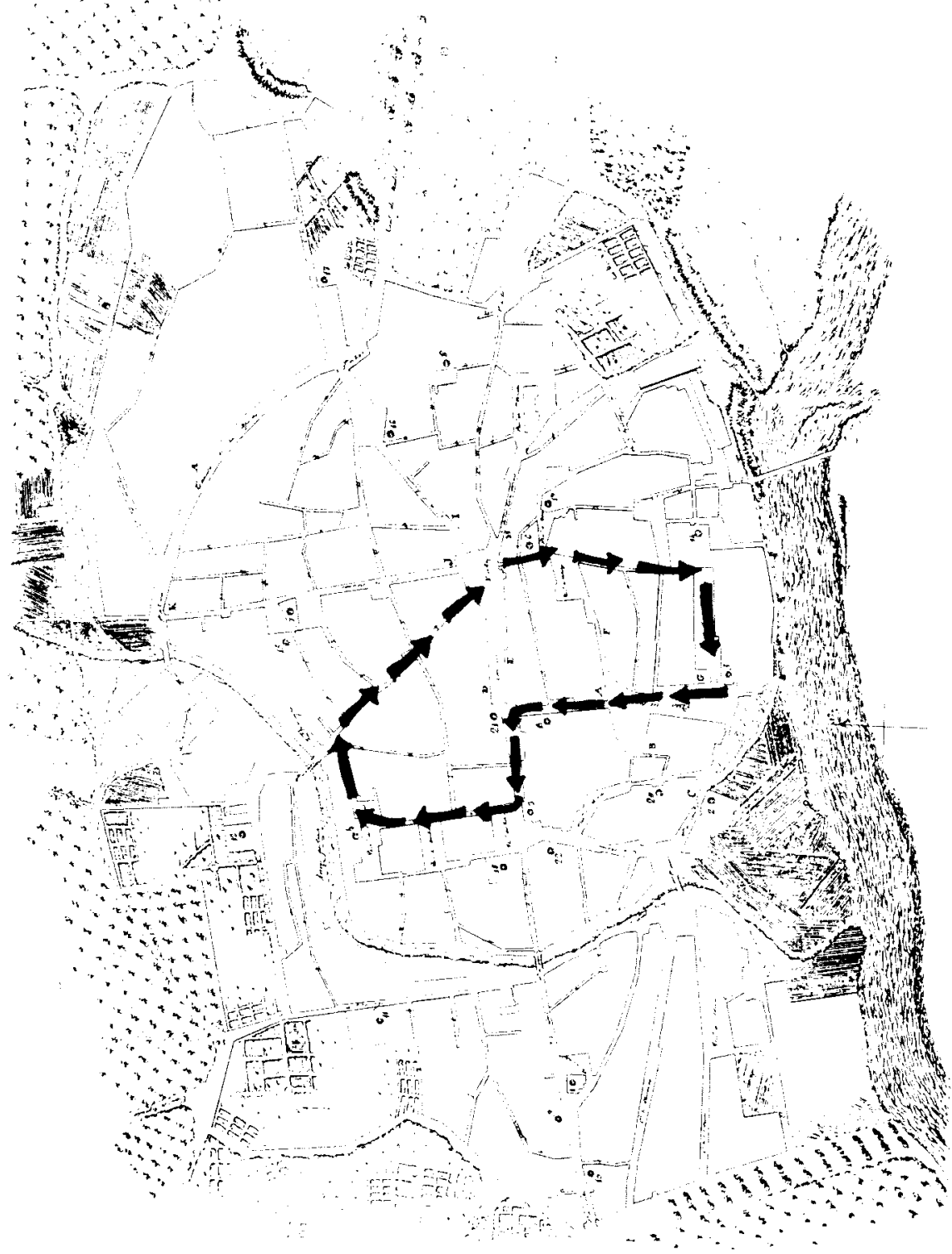

Plano 1. Itinerario de la procesión del Corpus de 1602. 


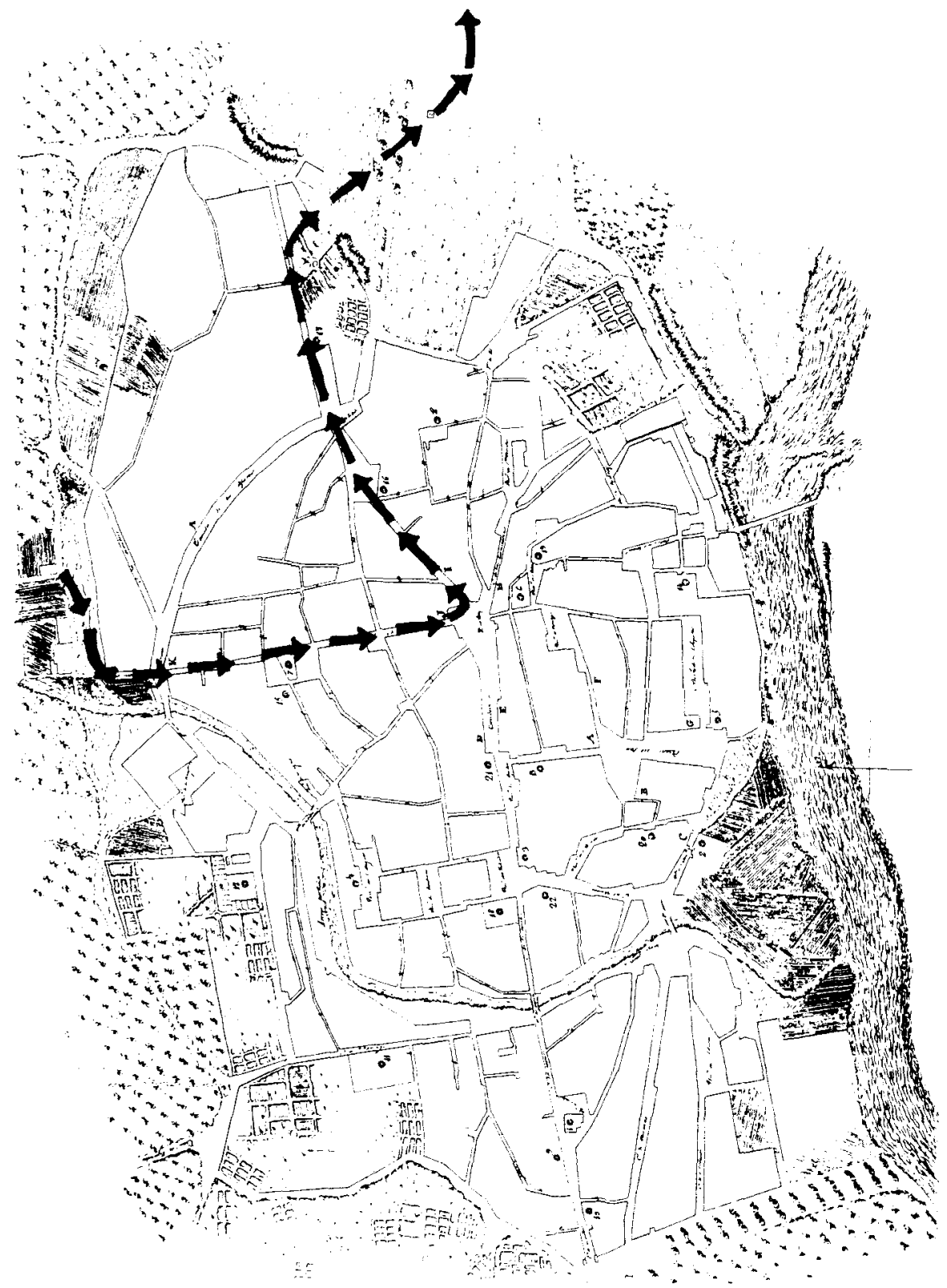

Plano 2. Itinerario de la procesión de los Gallegos en las Mondas durante el siglo xVII. 


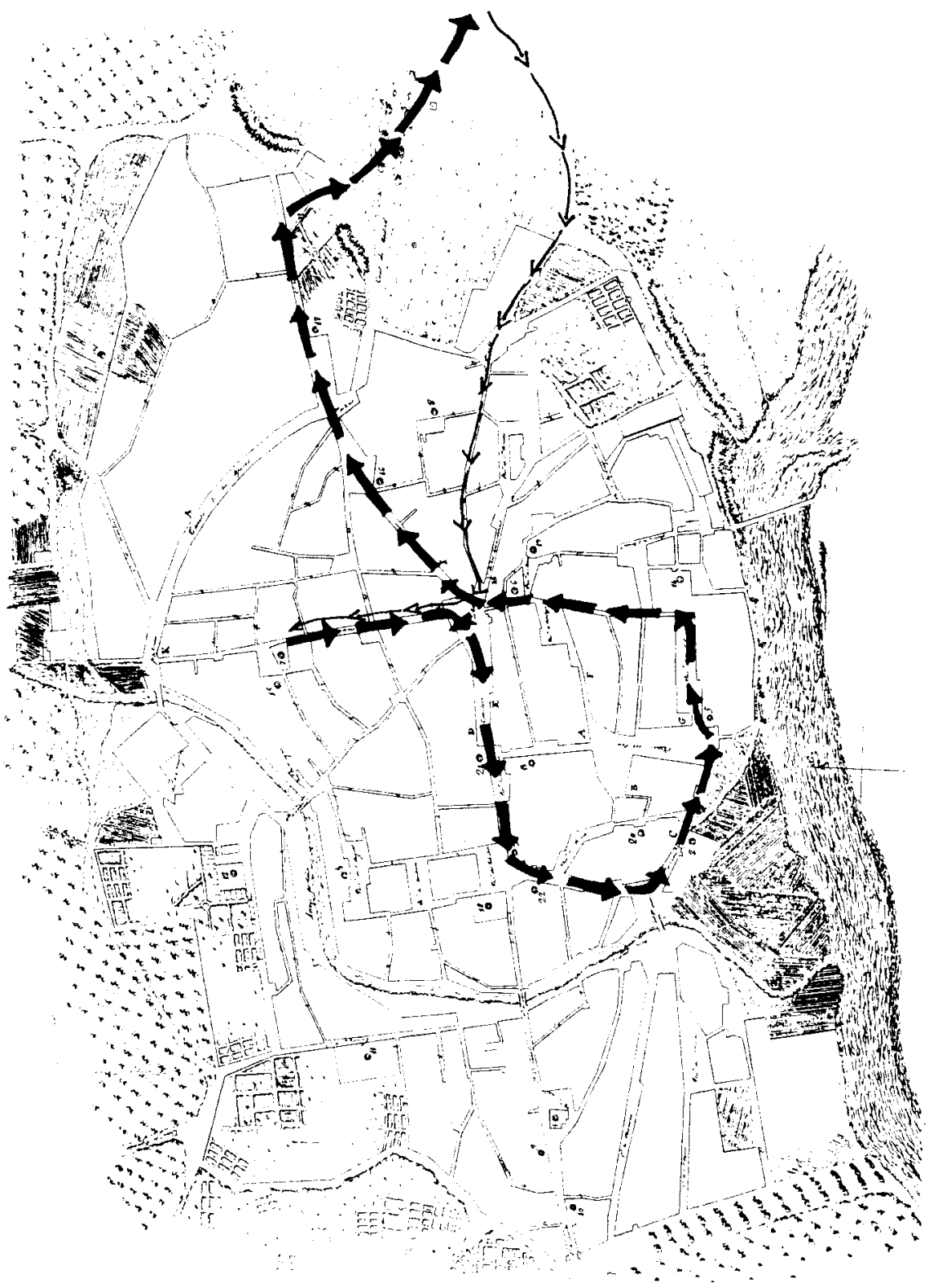

Plano 3. Itinerario del Cortejo de Mondas. Siglo xvil. 


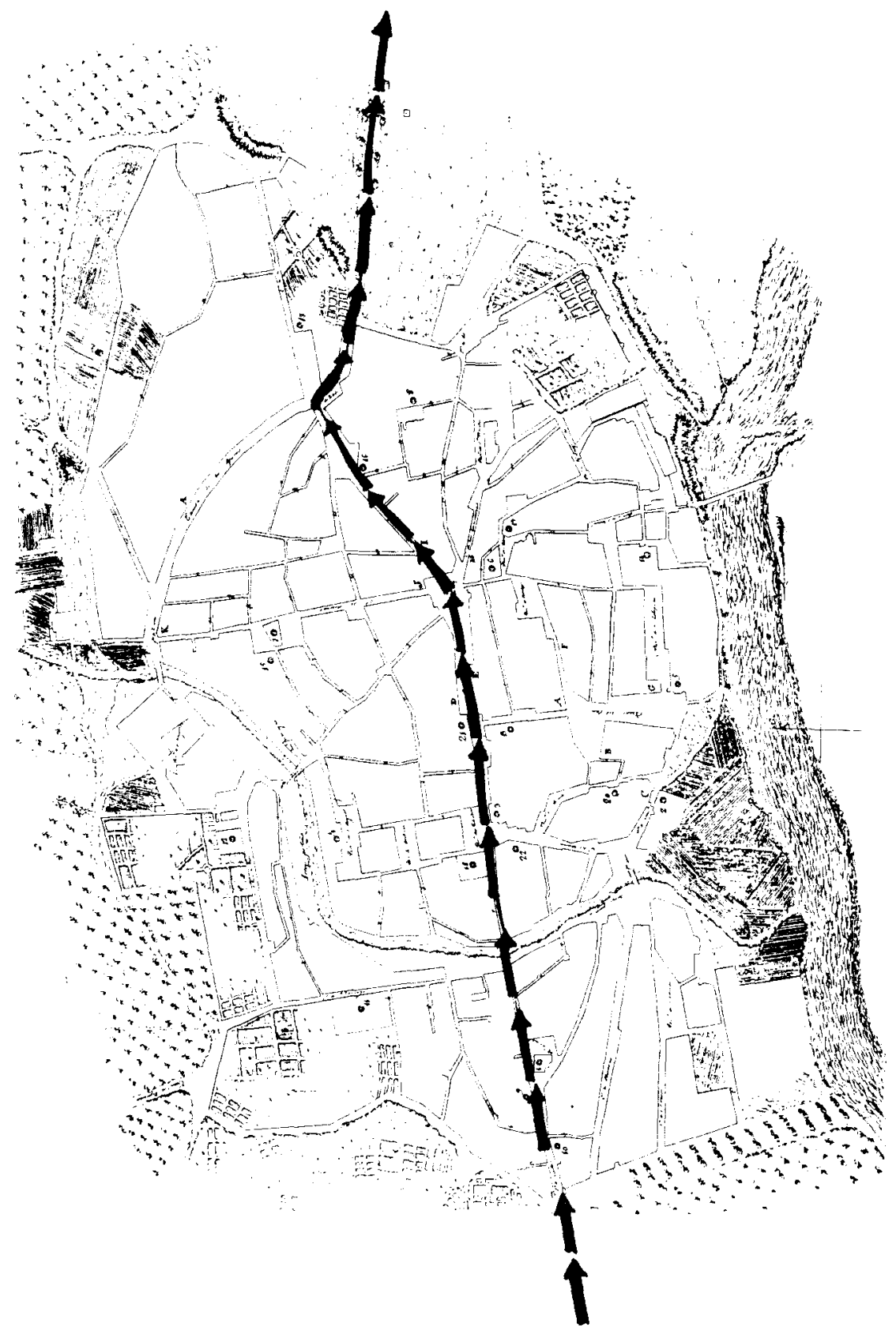

Plano 4. Paso de la reina de Portugal doña Mariana de Borbón por Talavera en 1777. 


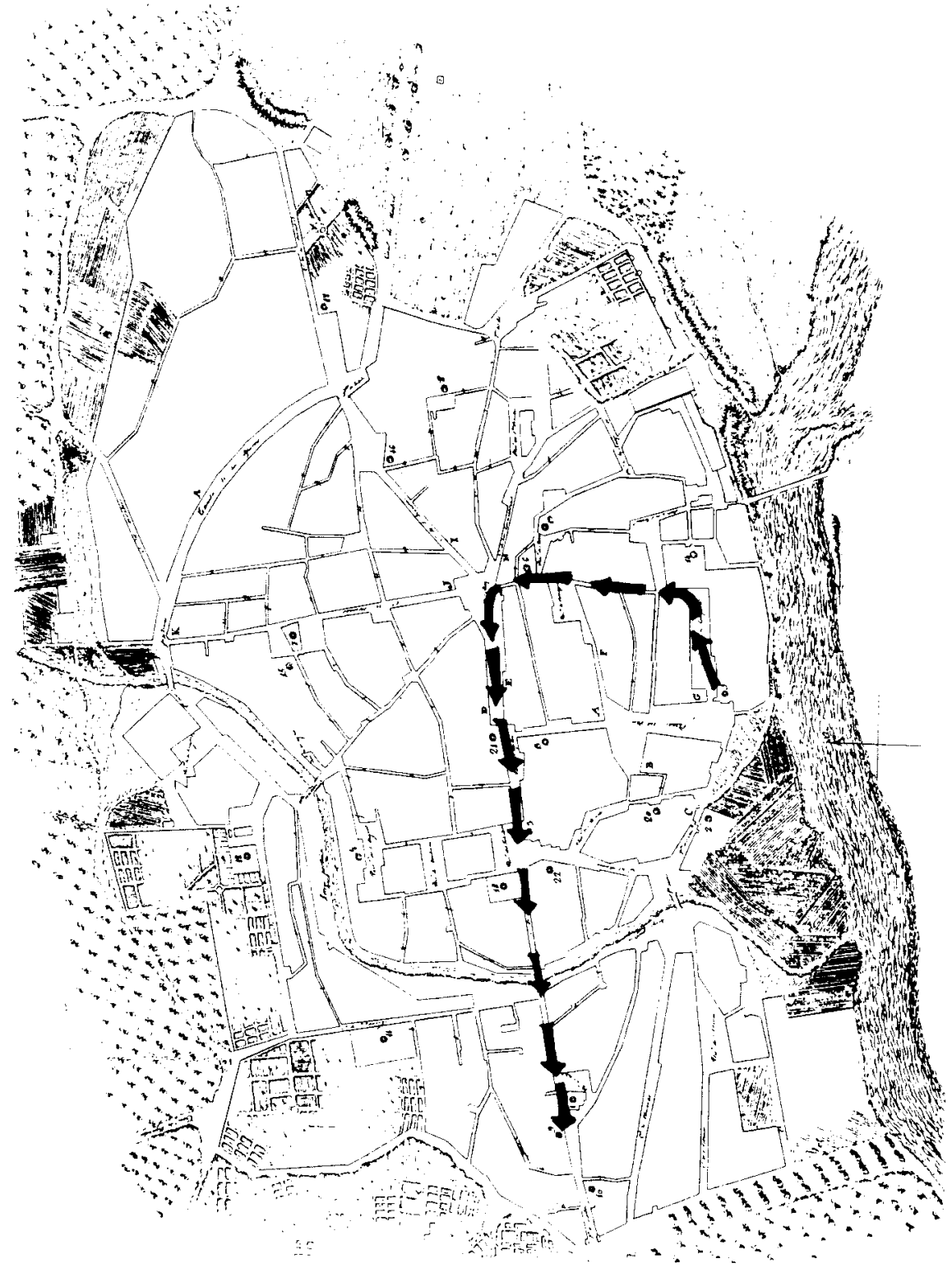

Plano 5. Itinerario de la procesión con motivo de la consagración de la iglesia del Convento de Padres Carmelitas en 1711. 